This article was downloaded by: [East Carolina University]

On: 2 September 2009

Access details: Access Details: [subscription number 908884216]

Publisher Routledge

Informa Ltd Registered in England and Wales Registered Number: 1072954 Registered office: Mortimer House, 37-41 Mortimer Street, London W1T 3JH, UK

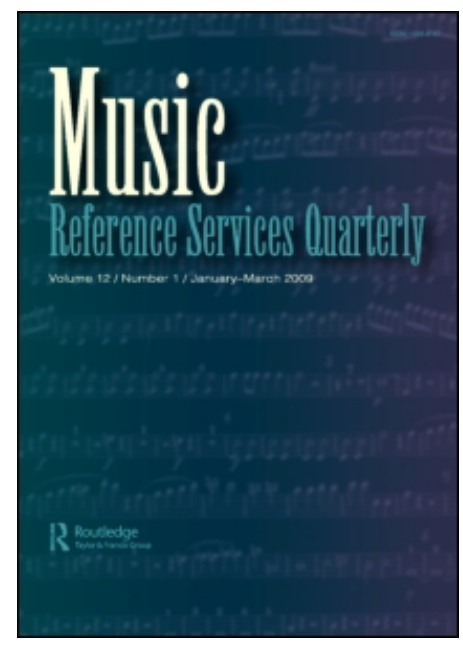

Music Reference Services Quarterly

Publication details, including instructions for authors and subscription information:

http://www.informaworld.com/smpp/title content=t792306936

\title{
Calling All Academic Music Library Reference Desks: A Follow-Up Study
}

Nara L. Newcomer; David Hursh

Online Publication Date: 01 August 2008

To cite this Article Newcomer, Nara L. and Hursh, David(2008)'Calling All Academic Music Library Reference Desks: A Follow-Up Study',Music Reference Services Quarterly,11:2,101 - 129

To link to this Article: DOI: $10.1080 / 10588160802143405$

URL: http://dx.doi.org/10.1080/10588160802143405

\section{PLEASE SCROLL DOWN FOR ARTICLE}

Full terms and conditions of use: http://www.informaworld.com/terms-and-conditions-of-access.pdf

This article may be used for research, teaching and private study purposes. Any substantial or systematic reproduction, re-distribution, re-selling, loan or sub-licensing, systematic supply or distribution in any form to anyone is expressly forbidden.

The publisher does not give any warranty express or implied or make any representation that the contents will be complete or accurate or up to date. The accuracy of any instructions, formulae and drug doses should be independently verified with primary sources. The publisher shall not be liable for any loss, actions, claims, proceedings, demand or costs or damages whatsoever or howsoever caused arising directly or indirectly in connection with or arising out of the use of this material. 


\title{
Calling All Academic Music Library Reference Desks: A Follow-Up Study
}

Nara L. Newcomer

David Hursh

\begin{abstract}
The East Carolina University Music Library established regularly staffed reference desk service and studied whether the presence of a reference desk increased patron comfort level in seeking assistance even when the reference desk was unstaffed. Reference activity statistics and results from a patron survey indicate that the reference desk strengthened reference service during hours the desk was staffed but did not increase patron comfort level at times the desk was unstaffed. This article presents key components of music library reference service highlighted by the survey and makes recommendations for other music libraries considering implementing or continuing reference desk service.
\end{abstract}

KEYWORDS. Music libraries, personnel, reference desks, reference services

\section{INTRODUCTION}

The reference desk - a distinct, clearly labeled, and regularly staffed desk separate from the circulation desk - is a standard feature

Nara L. Newcomer is Assistant Music Librarian, and David Hursh is Head Music Librarian, both at East Carolina University, Greenville, NC.

The authors would like thank the following people for their assistance with this project: Dorothy Clayton, Harry Frank, Tracy Jones, and Emily Smith.

Music Reference Services Quarterly, Vol. 11(2) 2008

Available online at http://www.haworthpress.com

(C) 2008 by The Haworth Press. All rights reserved. doi: $10.1080 / 10588160802143405$ 
in general libraries of all types. Reference desks are not, however, a standard feature of American academic music libraries. In 2004, David Hursh, Head Music Librarian at East Carolina University (ECU), in Greenville, North Carolina, surveyed American academic music libraries and found that less than a quarter $(22 \%)$ had a reference desk as defined above. In the article reporting that study's results Hursh theorized, "if music librarians advertised their availability by sitting at a reference desk in the public-service area for a few hours each week, students would feel more comfortable asking for assistance, even when the librarian is not at the desk.", Hursh did not, however, test this theory.

The present article reports the results of another study conducted at the East Carolina University Music Library investigating Hursh's theory. ${ }^{2}$ In addition to analysis of patrons' information-seeking behavior preference as evidenced by reference activity statistics and a survey, this article explains how the ECU Music Library established its first regularly staffed reference desk. ${ }^{3}$ Furthermore, this article presents the components of music library reference desk service highlighted by the study and offers related recommendations for other music libraries considering implementing or continuing reference desk service.

\section{LITERATURE REVIEW}

Only three published studies deal with reference service in music libraries. The first of those studies surveyed forty-five music libraries on the virtual reference services they provided and so by design excluded examination of the role of a physical reference desk. ${ }^{4}$ The second study measured effectiveness in answering reference questions at thirteen music libraries using the Wisconsin-Ohio Reference Evaluation Program (WOREP) survey instrument. ${ }^{5}$ That study considered (among other factors) the type of staff member (librarian, paraprofessional, or student) answering the question and found that student employees answering reference questions in music libraries had a consistently negative effect on reference success. The presence or absence of a music library reference desk was not considered as a factor affecting reference performance.

Hursh's study, described in the first paragraph of this paper, was the third of these three earlier studies. Hursh did not consider 
reference success but surveyed American academic music libraries and found that only $22 \%$ had a "distinct, clearly labeled, and regularly staffed [reference] desk separate from the circulation desk." 6 Hursh identified six factors related to the presence of reference desks in American academic music libraries: (1) level of degrees offered by the institution, (2) enrollment of music majors at the institution, (3) number of music library staff members, (4) size of the music collection, (5) size of the music library, and (6) philosophy of music library staff members with regard to maintenance of a reference desk. ${ }^{7}$ The first five factors all pointed to one conclusion: larger, better staffed music libraries tended to have reference desks, whereas smaller, more thinly staffed music libraries tended not to have reference desks. The study also found that music libraries as a whole tended to be small. Nearly half had collections of less than 20,000 items, and only $60 \%$ had at least one professional music librarian on even a part-time basis. ${ }^{8}$

In addition to these three studies a somewhat larger (though still small) body of literature outlines "best practices" in music reference service. Although these papers do not report on systematic studies, many contain valuable insights from experienced music librarians. Most of these articles are general in nature or focus on sources and techniques for effective reference transactions and collections rather than on the effect of a reference desk. ${ }^{9}$

Given the extremely small body of literature relating to reference service in music libraries, it is worthwhile to consider the larger arena of general academic library reference service, specifically the areas of reference performance and service point configuration. Because reference desks remain a standard feature of general academic libraries, reference performance has been a frequent subject of research and debate. However, the major portion of this literature focuses on the success of reference transactions based on the performance of the librarian. Few studies have considered the library environment as a factor in reference success, and when they do consider the library environment, the reference desk's existence is assumed and discussion centers on different possible designs. ${ }^{10}$ No published studies consider the effect of the presence or absence of a reference desk on reference success in any type of library.

While the present study investigated a double service point configuration, some posit that library patrons are better served by 
either (1) a single service point, or (2) the referral method. With a single service point a reference librarian is one among numerous people available at one service desk. With the referral method a distinct reference desk exists but is staffed by students or paraprofessional staff who refer questions to librarians as appropriate. Proponents of the referral method argue that patrons benefit because staff time is reallocated to more beneficial pursuits. ${ }^{11}$ Among libraries that implemented either of these models, none published concrete data as to their success or failure. ${ }^{12}$ This study takes a step toward filling that void.

\section{BACKGROUND}

Demographically, the ECU Music Library is similar to many academic music libraries. ${ }^{13}$ Like $88 \%$ of U.S. academic music libraries it is organizationally a department of the main university library, and like $44 \%$ of them it is physically located in the same building as the music program. ${ }^{14}$ The Music Library's academic year operating hours (seventy-nine a week) align it with $49 \%$ of similar academic music libraries. ${ }^{15}$ The ECU Music Library's staffing level, however, exceeds the norm for similar libraries and consists of two full-time librarians, three full-time paraprofessionals, and numerous part-time undergraduate and graduate student assistants. ${ }^{16}$

Before 2006, the ECU Music Library did not have a regularly staffed reference desk. The library did, however, provide reference service and used the circulation desk, staffed primarily by undergraduate student assistants, as the main point of contact. This method hybridizes the single service point and the referral method discussed in the literature review, and is, in all likelihood, the method by which most academic music libraries provide reference service. Hursh's 2004 study supports this supposition: 92\% of American academic music libraries had at least one person authorized for music reference, but only $22 \%$ had a separate and distinct reference desk. ${ }^{17}$

At the ECU Music Library, signs throughout the facility encourage patrons to request assistance from a full-time staff member, but staff members observed that most patrons came to the circulation desk and simply questioned the first person they 
encountered, thus placing the burden upon student assistants to correctly refer inquiries. Student assistants were trained to only answer directional questions (e.g., Where is the copy machine?) and refer reference questions (e.g., How do I find information on popular music?) to a full-time staff member. ${ }^{18}$ Nonetheless, student assistants constantly attempted to answer reference questions, often giving the patron unhelpful or inaccurate information or wasting a great deal of the patron's time before enlisting the aid of a full-time staff member. The weakness of this hybrid method of reference service, underscored by results from Christensen, Du Mont, and Green's study, ${ }^{19}$ led the ECU Music Library to seek a better method: establishment of a separate, regularly staffed reference desk.

However, despite being relatively well staffed, it was unfeasible for the ECU Music Library to provide reference desk service during hours comparable to those normally maintained by general academic libraries. Therefore, the ECU Music Library staffed the reference desk for only a few hours a week, with a twofold goal: (1) to provide reference desk service during hours of heaviest use, and (2) to advertise the availability of full-time staff members even when the reference desk was not staffed.

\title{
METHODOLOGY
}

In January 2006, the ECU Music Library inaugurated its first regularly staffed reference desk. The desk was located in the reference section and staffed nine hours a week, with desk duty split between ECU's two professional music librarians. Reference activity statistics from the past two and one-half years revealed that the library's busiest two-hour blocks were 10:00 a.m. to noon, noon to 2:00 p.m., and 2:00 to $4: 00$ p.m. ${ }^{20}$ Librarians staffed the desk as follows:

\author{
Reference Desk Hours During Fall and Spring Semesters \\ Monday 11:00 a.m.-noon; 2:00-3:00 p.m. \\ Tuesday 1:00-3:00 p.m. \\ Wednesday 1:00-3:00 p.m. \\ Thursday 11:00 a.m.-noon; 1:00-2:00 p.m. \\ Friday 11:00 a.m.-noon
}


This schedule distributed the nine weekly hours of reference desk service evenly throughout the periods of heaviest demand by scheduling three desk hours during each of the three busiest twohour blocks. The nine hours were also spread among the days of the week, with a librarian manning the reference desk for two hours daily Monday through Thursday and one hour on Friday.

To ensure statistical validity, reference desk service continued through the entire 2006 year, including break periods and summer sessions. Although the number of reference desk hours during the summer sessions matched those of the academic year, the summer session hours were scheduled to coincide with summer peak use hours, as indicated by statistics from previous years and were as follows:

\begin{tabular}{|c|c|}
\hline Reference D & Hours During Summer Sessions \\
\hline Monday & 11:00 a.m.-noon; 5:00-6:00 p.m. \\
\hline Tuesday & 3:00-5:00 p.m. \\
\hline Wednesday & 11:00 a.m.-noon; 5:00-6:00 p.m. \\
\hline Thursday & 3:00-5:00 p.m. \\
\hline Friday & 11:00 a.m.-noon \\
\hline
\end{tabular}

Music Library staff members were concerned that patrons would think they could only ask questions during hours the reference desk was staffed or might become confused about where to go for assistance. To preempt such scenarios, library staff members placed a large, brightly colored sign above the reference desk encouraging patrons to ask questions and to request a full-time staff member at the circulation desk when the reference desk was unstaffed (Figure 1). In addition to being posted below this sign, reference desk hours were also advertised on the Music Library's website.

As discussed in the literature review, reference success has never been evaluated with regard to the impact of the presence of a reference desk. Therefore, commonly employed measures such as answer accuracy and user satisfaction levels were not appropriate for this study and a "Willingness to Return" method was utilized. Durrance's "Willingness to Return" study found that a patron's willingness to return to the same librarian with future questions is a useful measure of success. ${ }^{21}$ Similarly, the current study proposed that a patron's willingness to ask for the assistance of a full-time staff 
FIGURE 1. Sign above reference desk

\section{. \\ Ask

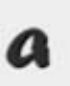 \\ Music LiGrarian

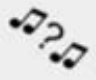

During the hours posted below, a lbrarian will be here at the Reference Desk to answer questions.

Have a question at another time? No problem - just ask at the Circulation Desk for a full-time staff member.

member when the reference desk is not staffed is a useful measure of the effect of the presence of a reference desk. The current study used two methods to measure this comfort level: (1) the analysis of reference activity statistics, and (2) a patron survey.

The ECU Music Library recorded exact reference statistics beginning September 2003, indicating number of questions, type (directional, technical, reference, or consultation), ${ }^{22}$ and method (in person, telephone, or e-mail). After establishing reference desk service, library staff members continued to record reference activity statistics as in the past, and tracked questions asked at the reference desk as a distinct subset.

The one-page survey recorded each patron's likelihood (willingness) to pursue help from various sources (see Appendix A). In addition to collecting demographic data, the survey gathered information on respondents' awareness of the reference desk, whether they had ever used the reference desk, and their likelihood of pursuing various courses of action to obtain library assistance. The survey presented respondents with three scenarios: (1) the reference desk exists and is staffed, (2) the reference desk exists and is unstaffed, and (3) the reference desk does not exist. Four or five courses of action involving either expert assistance (a professional music librarian or a music library paraprofessional) or non-expert assistance (e.g., a library student assistant, professor, or classmate) of either an immediate or delayed nature accompanied each scenario. Respondents were given a four-point Likert-type scale to rate their likelihood of pursuing courses of action, which were configured to allow comparison across the scenarios. The four ratings were: "very likely," "somewhat likely," "somewhat unlikely," and "very unlikely." 
In the staffed reference desk scenario, five courses of action for obtaining assistance were available to respondents. Three courses resulted in immediate assistance from library staff members (either expert or non-expert): (1) "ask the librarian at the reference desk," (2) "seek out a full-time staff member elsewhere in the library," and (3) "ask a student worker at the circulation desk to help you." A fourth course of action, "ask someone else (professor, classmate, etc.)," provided immediate assistance only if that "someone else" happened to be in the library. The final course of action available was "give up."

In the unstaffed reference desk scenario, five courses of action were again available to respondents, but only two of these provided immediate assistance from library staff members (either expert or non-expert): "seek out a full-time staff member elsewhere in the library" or "ask a student worker at the circulation desk to help you." A third course of action, "come back later when a librarian will be at the reference desk," yielded expert, but not immediate, assistance. As in the staffed reference desk scenario, the final two options were "ask someone else (professor, classmate, etc.)" and "give up."

The final scenario asked respondents to recall their behavior before the establishment of the reference desk in January 2006. Only respondents who had visited the library before January 2006 were directed to answer this question. The courses of action were the same as those used in the unstaffed reference desk scenario, except that the "come back later when a librarian will be at the reference desk" course of action was not available.

Music Library undergraduate and graduate student assistants tested the survey instrument, and it was then distributed to library patrons during the week of November 27, 2006. This week was chosen because it is typically a high-traffic week and occurs late enough in the semester that students had likely conducted research requiring reference assistance. The survey was conducted in the Music Library because this study dealt with the effect of the presence of a physical reference desk on users who were physically in the library. During forty of the seventy-nine Music Library operating hours, student assistants stationed near the library entrance asked each entering patron to complete the survey. Only one survey was collected per patron, even if the patron entered multiple times during the survey period. 
A total of 152 surveys were collected, and though this number may seem small, it is actually representative. Most surveys were completed in the first few days of the week, and by the end of the survey period most entering patrons had already completed the survey.

The survey data were analyzed using accepted statistical methods. When conducting statistical analysis the difference between compared frequencies must cross a predefined threshold of magnitude to be considered statistically significant (i.e., indicative of a real relationship rather than a chance occurrence). For the purposes of this study, the predefined threshold was set at .05 , the level of statistical probability commonly used for social science research. ${ }^{23}$ Both Chi Square ${ }^{24}$ and the Table of Significant Differences Between Percentages ${ }^{25}$ were used to determine whether differences crossed the .05 threshold and thus achieved statistical significance.

\section{FREQUENCIES}

\section{Reference Activity Statistics}

Reference activity during the first semester of reference desk service (Spring 2006) increased by 30\% from the previous spring, whereas activity in the second semester of reference desk service (Fall 2006) decreased by $70 \%$ in comparison with the previous fall semester. Although this extreme fluctuation may seem strange, statistics from previous years reveal that wide swings in reference activity levels are common for the ECU Music Library (Figure 2).

Total reference activity decreased steadily over the course of the first year of reference desk service. However, reference desk activity remained relatively constant (other than decreasing during the break months of May-August and December) (Figure 3).

\section{Survey}

Demographically, the survey response population was broken into the following groups: freshmen, sophomores, juniors, seniors, graduate students, faculty, staff, and other patrons (Figure 4). The vast majority of the respondents were students $(93 \%)$, predominantly undergraduates $(81 \%){ }^{26}$ Freshmen and seniors together comprised 
FIGURE 2. Reference activity by semester

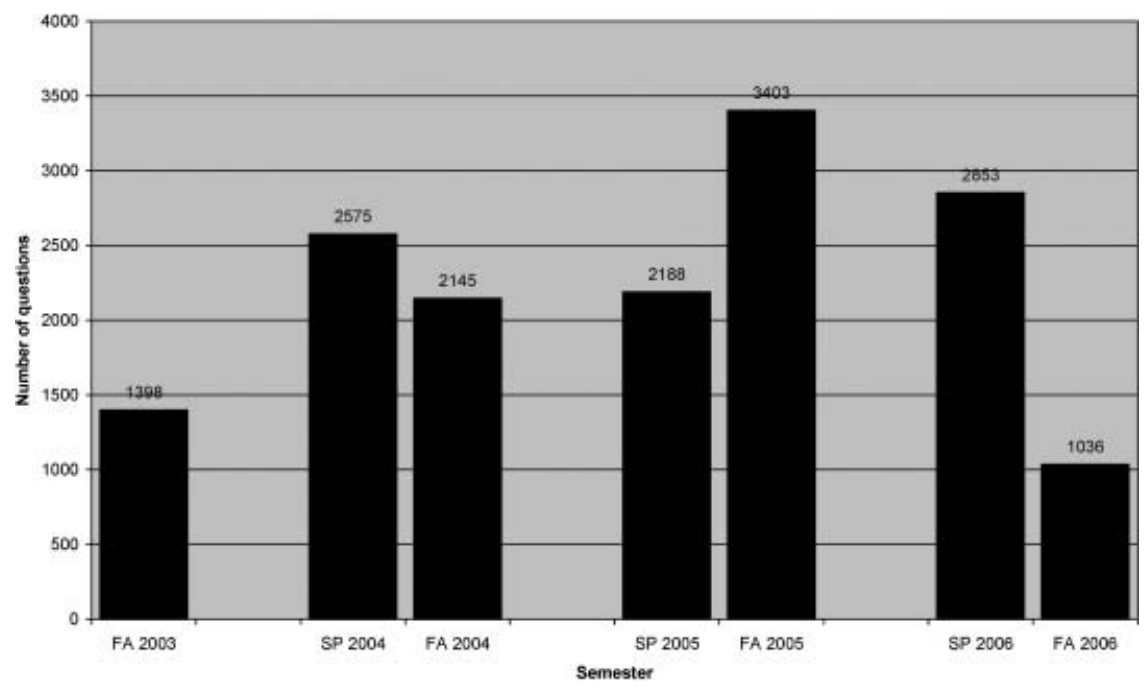

FIGURE 3. Reference activity for first year of reference desk service

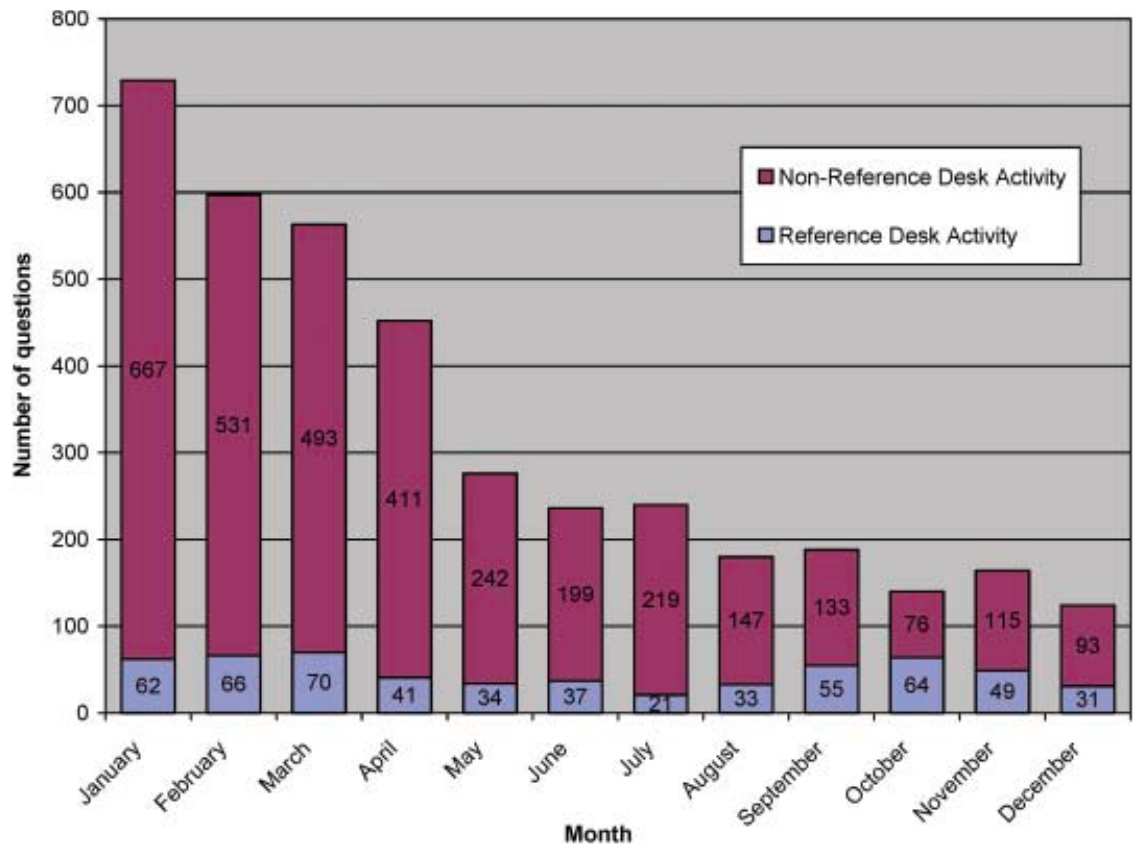


FIGURE 4. University classification of respondents

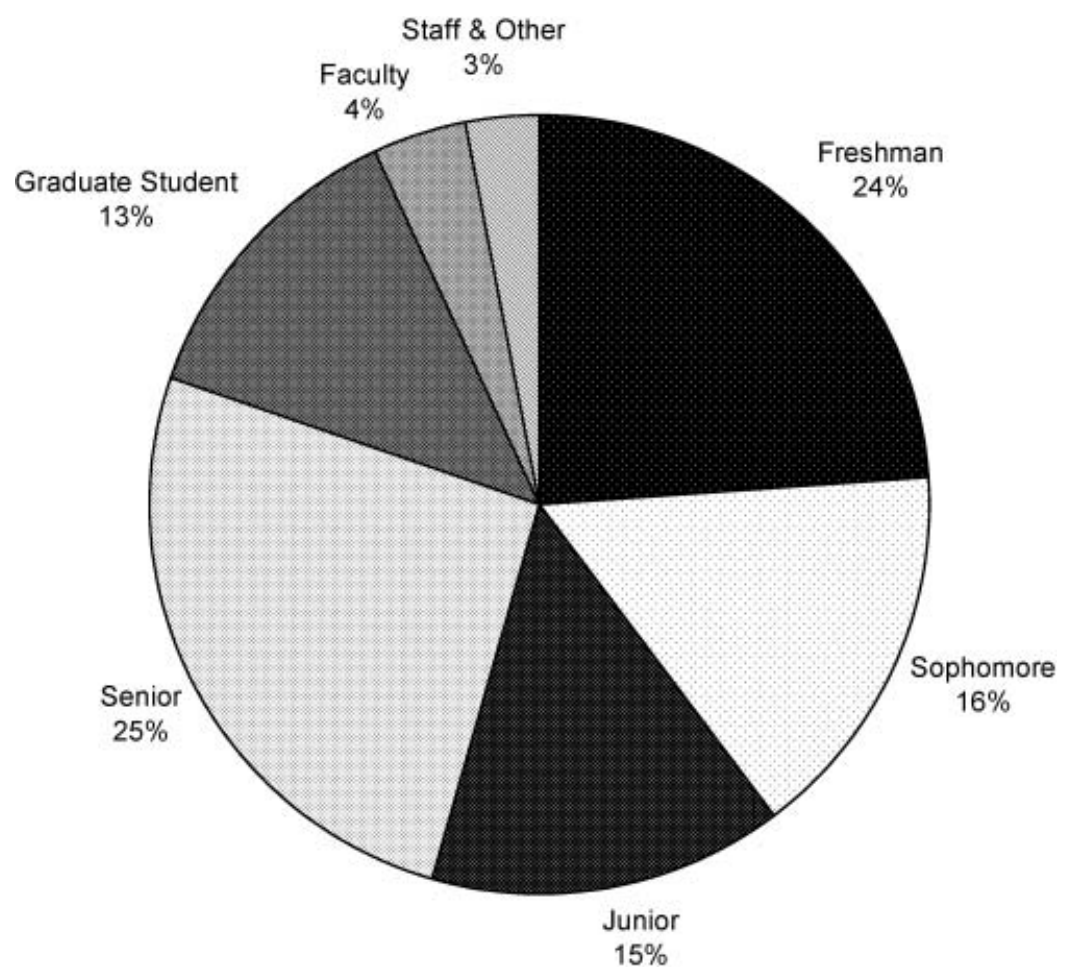

half $(50 \%)$ of the total response population, and $7 \%$ of the population consisted of faculty, staff, and other patrons.

As expected, frequent library visitors accounted for the major portion of survey respondents (Figure 5). Two-thirds $(66 \%)$ of respondents indicated they visited the Music Library "daily, or most days," and an additional 22\% visited "weekly" for a total of $88 \%$ visiting at least weekly. Though the week-long survey period may have resulted in over-sampling those who visited at least weekly, the resulting data support what Music Library staff members have long observed: At any given time, most of the people in the library are regular library users.

Nearly all respondents (96\%) stated they were aware of the reference desk, indicating the success of the Music Library's reference 
FIGURE 5. Frequency of music library visits

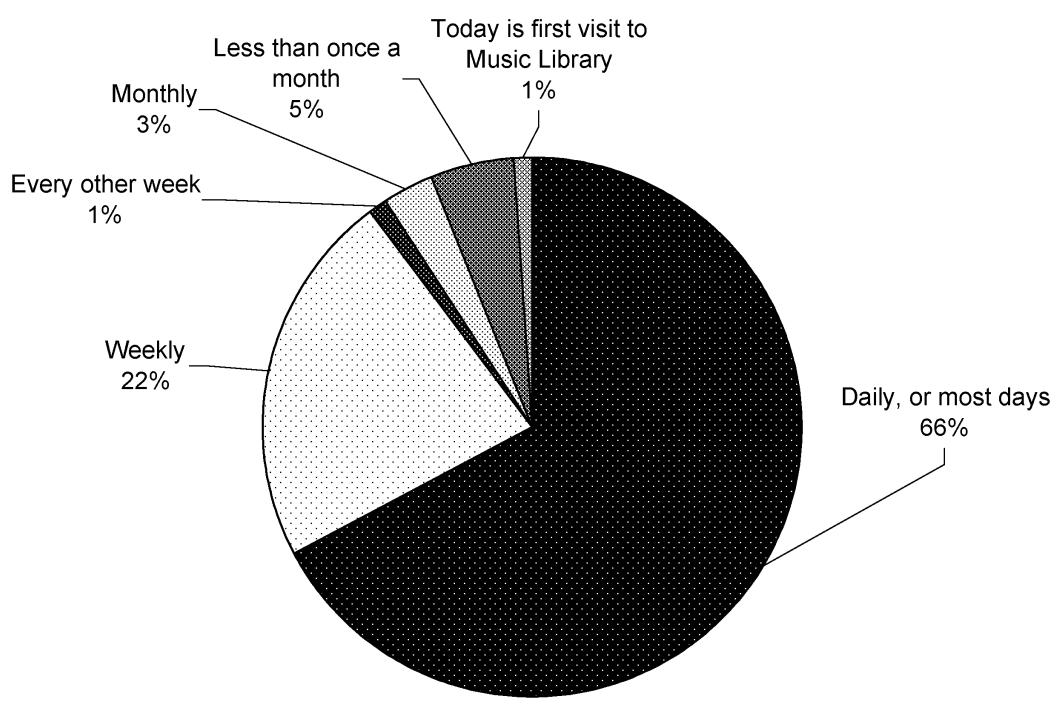

desk advertising efforts. However, patrons who knew about the service did not necessarily use it: just over half $(57 \%)$ had asked a question at the reference desk.

In the staffed reference desk scenario, patrons pursued a variety of courses of action. At least $72 \%$ of respondents stated they would be "very likely" or "somewhat likely" to choose the following courses of action: "ask the librarian at the reference desk" (83\%), "seek out a full-time staff member elsewhere" (72\%), or "ask a student worker at the circulation desk" (84\%). Fewer respondents $(60 \%)$ were "very likely" or "somewhat likely" to "ask someone else," and only $12 \%$ were "very likely" or "somewhat likely" to "give up" (Figure 6).

In the unstaffed reference desk scenario, respondents indicated a reluctance to "come back later when a librarian will be at the reference desk," with only $46 \%$ "very likely" or "somewhat likely" to pursue this course of action. The percentages for the next two courses of action were similar to those from the staffed reference desk scenario: $74 \%$ were "very likely" or "somewhat likely" to 
FIGURE 6. Behavior when reference desk is staffed

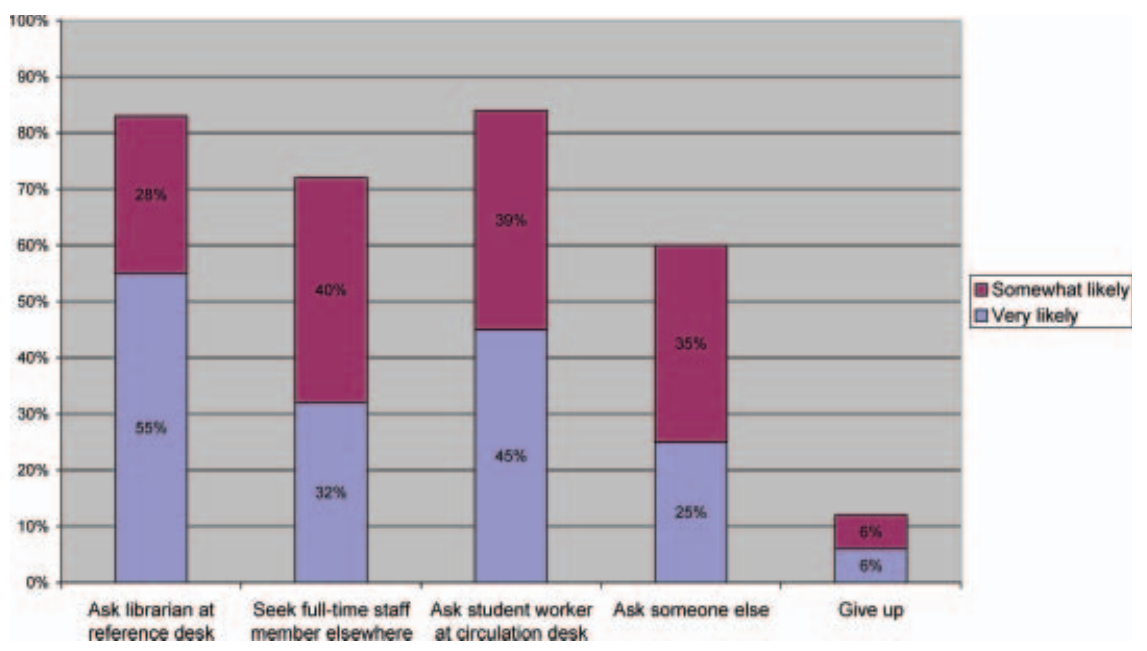

"seek a full-time staff member elsewhere," and 83\% were "very likely" or "somewhat likely" to "ask a student worker at the circulation desk." Seventy-one percent of respondents were "very likely" or "somewhat likely" to "ask someone else," and $16 \%$ stated they would be "very likely" or "somewhat likely" to "give up" (Figure 7).

In the scenario in which respondents were asked to recall their behavior before establishment of the reference desk, behavior was similar to both of the previous scenarios: $74 \%$ rated themselves "very likely" or "somewhat likely" to "seek a full-time staff member," and $86 \%$ were "very likely" or "somewhat likely" to "ask a student worker at the circulation desk." Sixty-eight percent were "very likely" or "somewhat likely" to "ask someone else," and only 17\% were "very likely" or "somewhat likely" to "give up" (Figure 8).

\section{STATISTICAL ANALYSIS}

Problems with the analysis of the reference activity statistics limited the usefulness of those data. However, the survey yielded meaningful 
FIGURE 7. Behavior when reference desk is unstaffed

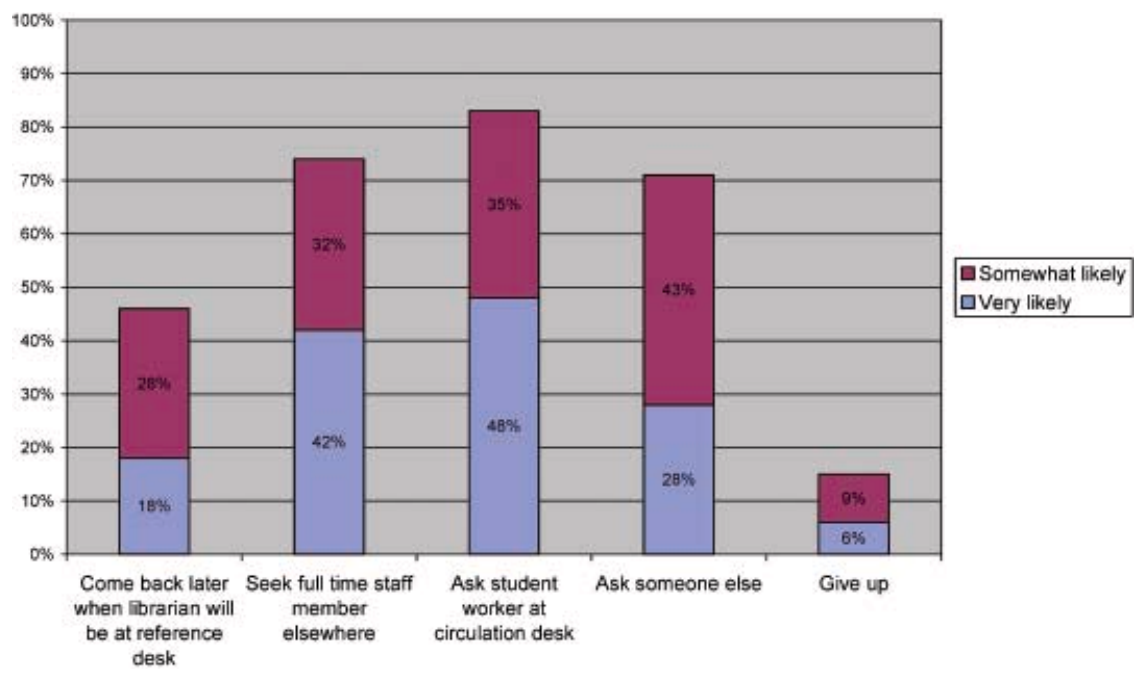

FIGURE 8. Behavior before reference desk

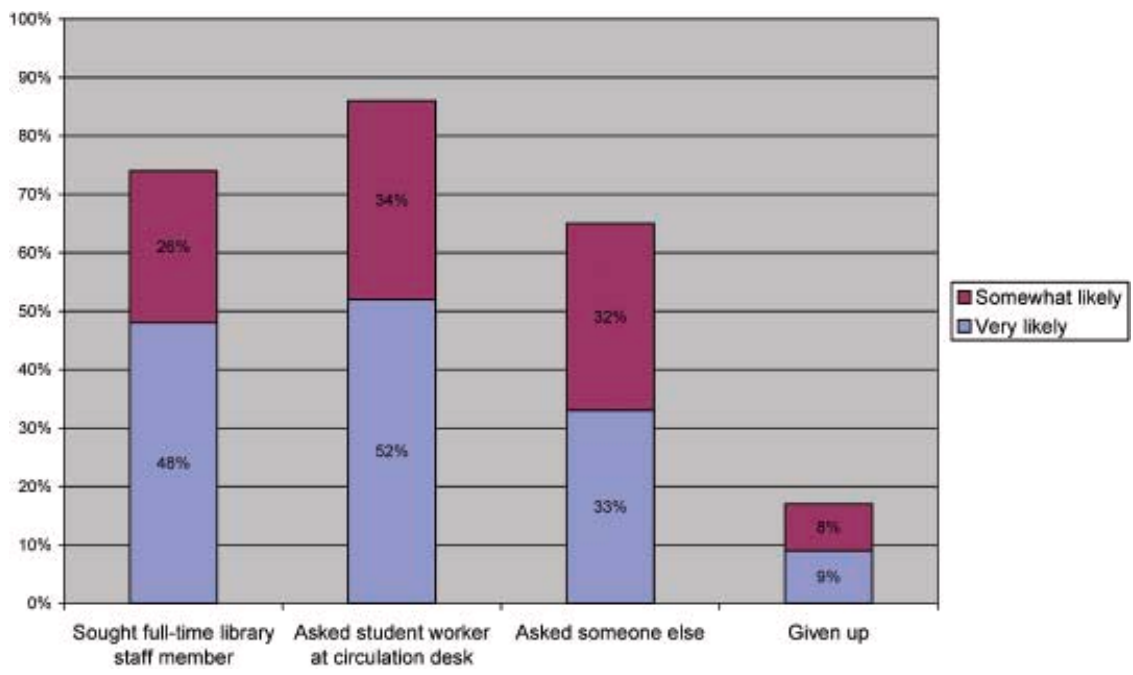


information and led to valuable conclusions. Both the factors creating the problems and the conclusions are discussed in the following text.

\section{Reference Activity}

The following factors complicated the analysis of the reference activity portion of this study and made it impossible to use reference activity statistics as a basis for observations about the reference desk's effect on patrons' assistance-seeking comfort levels when the desk is not staffed:

(1) Historically, the library's reference activity levels have fluctuated widely. These fluctuations could in part be caused by the irregular scheduling of research-intensive courses.

(2) Reference activity for the Fall 2006 semester dropped dramatically from the previous two semesters' levels. The cause might be that the Music Library's Daytime Access Services Supervisor resigned in August and the position remained unfilled through the end of the fall semester. The person in this position supervises circulation activities and is the only staff member whose desk is visible and accessible to patrons without entering the library's staff area. As a result, this person deals with a large portion of reference activity. When quick access to a full-time staff member was not apparent, patrons may not have bothered to ask for assistance, thus contributing to a low reference activity count.

Already established reference activity trends were not altered by the presence of the reference desk. These trends included (1) increased activity near research paper deadlines, (2) decreased activity during break periods, and (3) increased activity between 10:00 a.m. and 4:00 p.m. daily.

\section{Survey}

As discussed in the Methodology section, the survey involved several overarching comparisons: (1) before the reference desk versus after the reference desk, (2) expert assistance versus non-expert assistance, (3) staffed reference desk versus unstaffed reference desk, and (4) patrons who used the library before the reference desk versus patrons who only used it after. These comparisons interact in various ways to provide the findings given in the following text. 


\section{Behavior Before and After the Reference Desk: Expert Assistance}

The principal aim of the study was to investigate patron comfort level with seeking expert assistance (a professional music librarian or a music library paraprofessional) if a library has a reference desk, regardless of whether it is staffed at the exact time of a patron's need. Whether rendered before or after the reference desk, reference assistance quality (expert vs. non-expert) and immediacy played key roles in the behavior of survey respondents. Each of the three reference service scenarios featured in the survey included at least one course of action for obtaining expert assistance:

- Before the reference desk

Seek a full-time staff member

- After the reference desk-staffed

Ask the librarian at the reference desk

Seek a full-time staff member elsewhere in the library

- After the reference desk-unstaffed

- Come back later when a librarian will be at the reference desk

- Seek a full-time staff member elsewhere in the library

While these courses of action are similar in their provision of expert assistance, they differ in the level of immediacy. "Ask the librarian at the reference desk" is the most immediate, "seek a fulltime staff member" and "seek a full-time staff member elsewhere" are less immediate, and "come back later when a librarian will be at the reference desk" delays assistance entirely.

A comparison of the most and least immediate courses of action (i.e., "ask a librarian at the reference desk" and "come back later when a librarian will be at the reference desk") reveals a difference that is not only statistically significant but dramatically so. ${ }^{27}$ After the reference desk, respondents were considerably more often "very likely" to "ask a librarian at the reference desk" (51\%) than they were to "come back later" (19\%). Although both courses of action required little effort (to obtain assistance, a questioner needed only approach the reference desk), respondents showed a strong preference for immediate assistance. In fact, "come back later" (the only 
delayed course of action available for obtaining expert assistance) received by far the lowest likelihood rating across all scenarios and courses of action, with the exception of "give up." These findings support this study's theory (i.e., a reference desk will increase patron assistance-seeking comfort level) because a high number of respondents indicating a strong likelihood of returning later suggests patrons think they can only receive assistance from a librarian when one is at the reference desk. However, this was not the case (Figure 9).

Although respondents' strong preference for immediate assistance supports this study's theory, the results also indicate that the existence of the reference desk did not increase respondents' likelihood of seeking expert assistance elsewhere in the library when the reference desk was unstaffed. When the reference desk was unstaffed, the percentage of respondents who were "very likely" or "somewhat likely" to "seek a full-time staff member" was exactly the same $(74 \%)$ as before the reference desk. In fact, the percentage of respondents in these same likelihood rating groups was also $74 \%$ when the reference desk was staffed. This finding is surprising, because logic would lead one to conclude that patrons would choose the more immediate assistance of a librarian at the reference desk

FIGURE 9. Behavior preferences for obtaining expert assistance

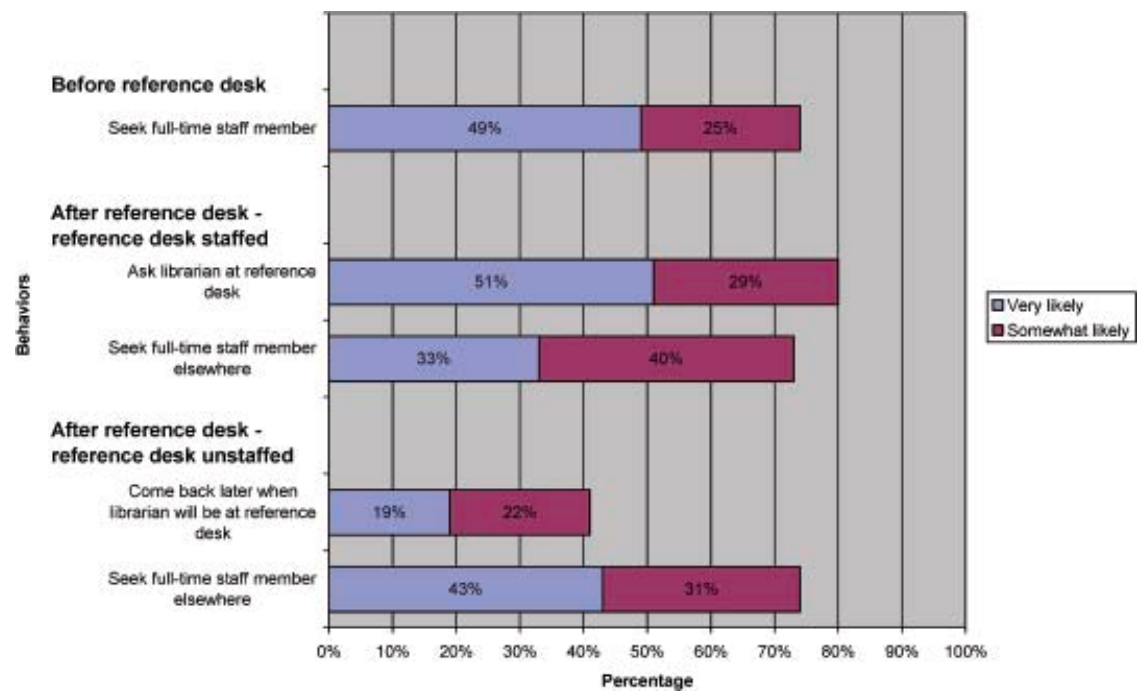


rather than seeking a full-time staff member elsewhere in the library.

However, individual examination of the "very likely" and "somewhat likely" categories in the "before the reference desk" and "after the reference desk - staffed" scenarios reveals a subtle but statistically significant difference. Before the reference desk, $49 \%$ of respondents were "very likely" and $25 \%$ were "somewhat likely" to "seek a full-time staff member." After the reference desk and when it was staffed, the "very likely" percentage decreased to $33 \%$, and the "somewhat likely" percentage increased to $40 \%$. This flip indicates that at the times the reference desk was staffed respondents were inclined to ask the librarian at the reference desk rather than seek expert assistance elsewhere in the library, suggesting that respondents perceived the librarian at the reference desk to be the preferred source of assistance (Figure 9).

\section{Behavior Before and After the Reference Desk: Non-Expert Assistance}

A secondary emphasis of this study was an investigation into whether the presence and staffing of the reference desk affected patrons' likelihood of choosing courses of action providing nonexpert assistance. The following three courses of action involving non-expert assistance were available in every scenario: (1) "ask a student worker at the circulation desk"; (2) "ask someone else (professor, classmate, etc.)"; and (3) "give up."

The differences among the percentages of respondents likely to "ask a student worker at the circulation desk for assistance" were not significant; indeed, the percentages are nearly identical in all scenarios and neither the presence nor staffing of the reference desk can be shown to have changed patrons' likelihood of seeking assistance from a student worker (Figure 10). Before the reference desk, $86 \%$ of respondents were "very likely" or "somewhat likely" to "ask a student worker at the circulation desk for assistance." After the reference desk, 85\% were "very likely" or "somewhat likely" to "ask a student worker" when the reference desk was staffed, and $84 \%$ were "very likely" or "somewhat likely" to do so when the reference desk was unstaffed.

These results parallel the findings regarding full-time staff members in the discussion on expert assistance (i.e., the presence of a reference desk did not affect respondents' likelihood of seeking 
FIGURE 10. Behavior preferences for obtaining non-expert assistance

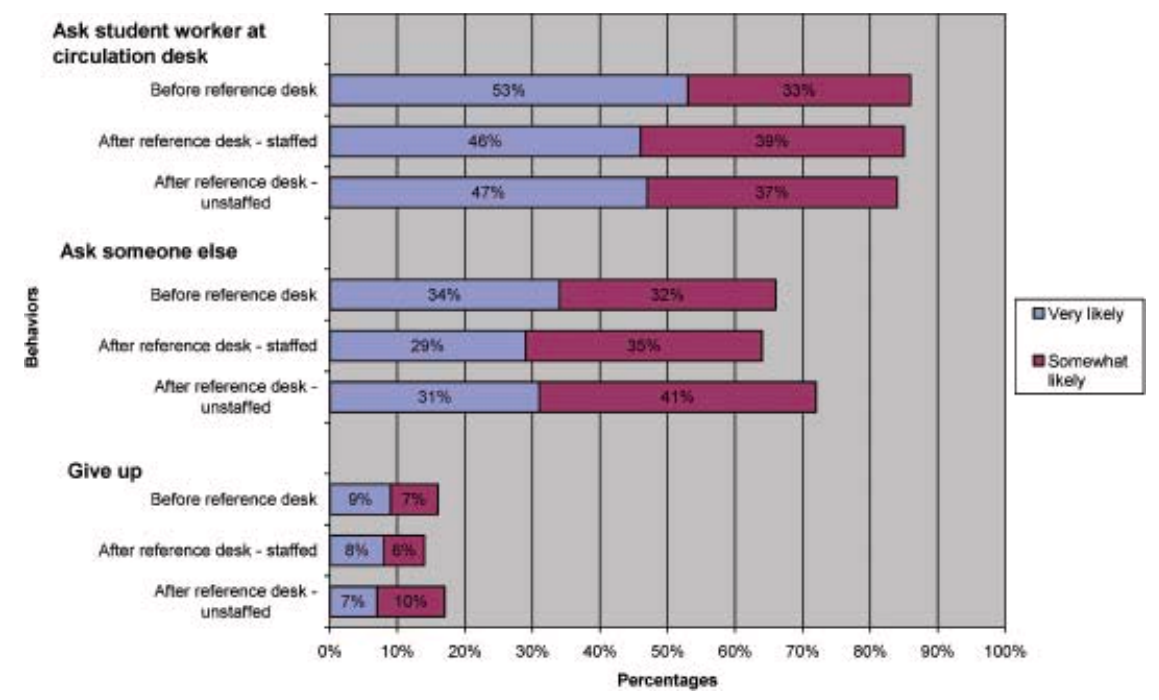

assistance from a full-time staff member elsewhere in the library) and are, on the surface, equally surprising. Why would patrons seek nonexpert assistance from a student worker when expert assistance was available only a few feet away in the form of a librarian at the reference desk? There are several possible reasons. First, student workers are fully qualified to answer many directional questions, and the survey did not distinguish between directional and reference questions. This might be an area for further investigation, though defining the various types of questions for respondents could be difficult. Second, the physical layout of the ECU Music Library meant that the circulation desk was immediately visible when a patron entered, but the reference desk was not visible. The reference desk was also not visible from the circulation desk, making it difficult for student workers at the circulation desk to know when to refer reference questions to the reference desk and when to call full-time staff members from their offices. Third, library employees staffed the circulation desk during all library operating hours, whereas the reference desk was staffed only nine hours a week. It seems logical that patrons would ask their questions at the most visible and constantly staffed location. 
Before the reference desk, $67 \%$ of respondents were "very likely" or "somewhat likely" to "ask someone else (professor, classmate, etc.)." After the reference desk, 63\% were "very likely" or "somewhat likely" to "ask someone else" if the reference desk was staffed, and $72 \%$ were "very likely" or "somewhat likely" to do so if the reference desk was unstaffed (Figure 10). While these percentages differ slightly, they do not achieve statistical significance. These findings may suggest that patrons tend to seek help from a non-library source slightly more frequently when the reference desk is unstaffed.

With regard to the "give up" course of action, $16 \%$ of respondents were "very likely" or "somewhat likely" to choose this option before the existence of a reference desk. After the reference desk, 14\% were "very likely" or "somewhat likely" to "give up" if the reference desk was staffed, and $17 \%$ were "very likely" or "somewhat likely" to do so if the reference desk was unstaffed. Again, the differences are not significant; in fact the percentages are nearly identical, and respondents' likelihood of giving up is not influenced by the presence or staffing of the reference desk.

\section{Those Who Did Not Visit Before the Reference Desk versus Those Who Did}

Thus far, this article has considered only respondents who visited the ECU Music Library both before and after establishment of the reference desk. The focus now turns to a comparison of these respondents with respondents who identified themselves as not having visited the Music Library prior to the reference desk and therefore had no experience using the library without the reference desk. This comparison deals only with the current behavior (i.e., behavior after establishing the reference desk) of the two groups. Dividing the respondents into these two groups reduced the number of respondents in each of the subsample groups, and the Table of Significant Differences Between Percentages required larger differences to achieve statistical significance. Although none of the comparisons exhibited statistical significance, several relationships did exhibit noteworthy differences that might have been statistically significant if the study included more respondents.

The first two noteworthy relationships follow the general principle of the difficulty in changing people's behavior; in other words, "old 
habits die hard." Of the two groups, those who had not visited before the reference desk were more often "very likely" to "ask the librarian at the reference desk" (64\% vs. 51\%). Additionally, when no librarian was at the reference desk the same group was more often "somewhat likely" to "come back later" (41\% vs. 22\%) (Figure 11). These differences suggest that it may be easier to shape the behavior patterns of incoming students than to adjust the established behavior of existing students. In other words, new students may benefit most from the presence of a reference desk.

As expected, those who had not visited before the establishment of the reference desk were predominantly new students: $67 \%$ were freshmen, and an additional $22 \%$ were graduate students, in all likelihood also incoming students. The fact that these new students were more often "somewhat likely" to "come back later" to get help is slightly disturbing. This finding suggests that new students may believe assistance is only available when the reference desk is staffed. Library staff members anticipated this possibility at the outset of the study and attempted to counteract it with the sign described in the Methodology section. This sign appears to have had an effect because, overall, fewer respondents were "very likely" or "somewhat

FIGURE 11. Those who did not visit before the reference desk versus those who did

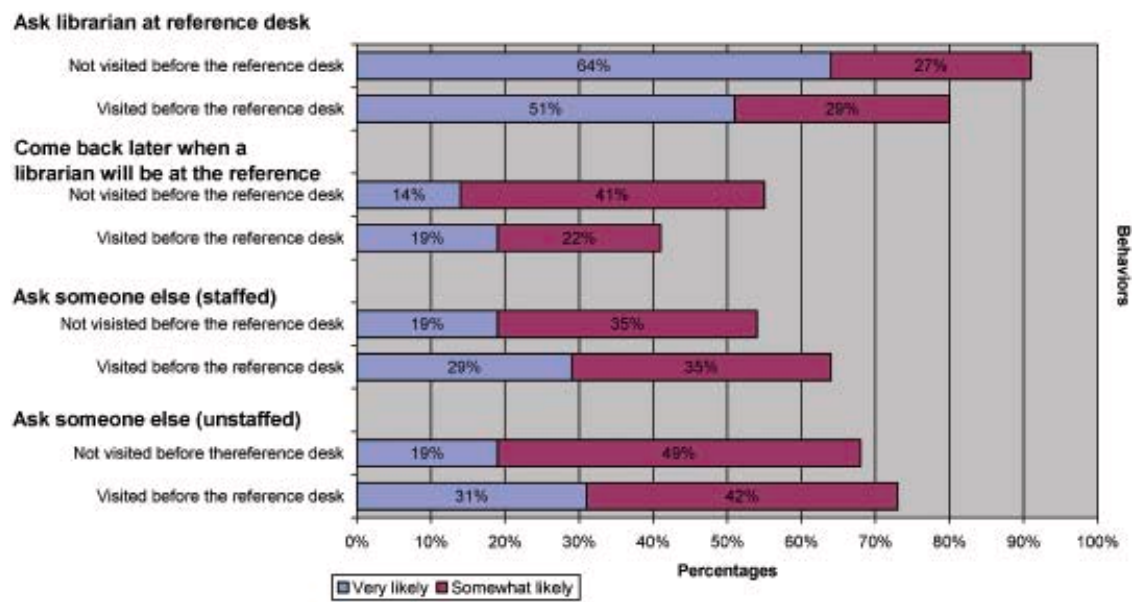


likely" to choose to "come back later" than they were to select these same ratings for any other course of action besides "give up."

Although the importance of signage should not be overlooked, another possibility is that in order to increase their comfort level new students simply need contact with full-time library staff members over time. Durrance's "Willingness to Return Study" supports this possibility through its finding that "interpersonal factors dominate in the observer's willingness to return to the librarian at another time.",28 Ironically, though provision of a reference desk is a way to encourage interpersonal contact, the possibility exists that it may make students less likely to ask for a full-time staff member when the reference desk is unstaffed. This suggests that music libraries providing reference desk service must use additional methods to advertise the availability of reference assistance even when the desk is unstaffed.

A third relationship, though less noteworthy than the first two, further supports the possibility of new students benefiting most from the presence of a reference desk. Of the two groups, the group consisting of those who had not visited before the reference desk was less often "very likely" to "ask someone else" regardless of whether a librarian was currently at the reference desk: $19 \%$ versus $29 \%$ when the reference desk was staffed; and 19\% versus 31\% when the reference desk was unstaffed. Although this difference may be primarily a characteristic of the demographic (incoming students have not yet established connections with faculty members and other students), it reiterates the possibility that new students may benefit more than others. Outreach in the form of a regularly staffed reference desk, even with limited hours, could go a long way toward filling this void.

\section{CONCLUSIONS}

As outlined in the following two conclusions, the results of this study showed the effect of a music library reference desk to be different than expected:

(1) The presence of a reference desk did not affect patrons' likelihood of seeking expert assistance from a full-time staff member elsewhere in the library when the reference desk was unstaffed. Study respondents were equally likely to pursue this course of action regardless of whether the reference desk was staffed, unstaffed, or non-existent. 
(2) The presence of a reference desk strengthened reference service during the hours that the desk was staffed. This study found that patrons strongly preferred immediate assistance. Therefore, when the reference desk was staffed they were more likely to request assistance there than they were to seek a full-time staff member elsewhere in the library. In addition, when the reference desk was unstaffed patrons preferred to seek expert assistance elsewhere in the library rather than save their query for a time when the reference desk would be staffed. These results are supported by Larason and Robinson's finding that patrons are more likely to use reference service when the physical cost is low. ${ }^{29}$ Therefore, although music library reference desks may not increase patron comfort with asking for expert assistance when the reference desk is unstaffed, they will improve overall reference service.

While this study's original theory was not supported by its findings, the benefits outlined in the second conclusion led the ECU Music Library staff members to continue providing regularly staffed reference desk service with attention to three reference service components: location, advertising, and patron behavior. The study's findings focused attention on these components and resulted in the following recommendations:

(1) Location is everything. The reference desk must be visible from as many areas of patron activity as possible. On the surface, this appears to be stating the obvious, but the space-challenged environment of many of today's music libraries means this recommendation must not be overlooked. ${ }^{30}$ Although the ECU Music Library staff members thought locating the reference desk in the reference area would be ideal, they found that visibility from multiple sightlines was more important than following traditional models. At the conclusion of this study the Music Library moved the reference desk to a location adjacent to the circulation desk and visible not only from the reference area but also upon entering the library, upon exiting the library's computer lab, from the library's study carrels, and from most of the circulating collection stacks.

(2) Advertising is essential. When staffing a reference desk for a limited number of hours, music libraries must actively advertise the availability of expert assistance when the reference desk is unstaffed. Neglecting to do this might actually result in a reference desk causing reference service to deteriorate, as patrons (especially new students) 
may think reference desk hours are the only times expert assistance is available. As discussed earlier, the ECU Music Library anticipated that promotion might be helpful, but the study's findings indicate it is necessary.

(3) Patience is a virtue. The results suggest that patrons were slow to change established information-seeking behaviors. Allow sufficient time when establishing music library reference desk service, and understand it may take several years to create new behavior patterns and realize the full impact of reference desk service.

In 2004 less than a quarter of American academic music libraries had reference desks, and a high number of the librarians staffing those libraries felt that even without a reference desk their reference service plan was effective. ${ }^{31}$ This study found that music librarians need not be satisfied with merely effective reference service. By establishing a reference desk and staffing it for just a few hours each week, even music libraries with limited resources can raise their reference service to a new level of excellence.

\section{NOTES}

1. David Hursh, "Calling All Academic Music Library Reference Desks," Music Reference Services Quarterly 8, no. 3 (2004): 64.

2. This study was granted exempt status by the Institutional Review Board of East Carolina University because it posed no more than minimal risk to participants and no information was recorded in such a manner that human participants can be identified in any way.

3. For a period in its history the Music Library designated a portion of its circulation desk as a reference desk, but, to the best of the authors' knowledge, the location was not regularly staffed.

4. Gerald Szymanski and Mary Alice Fields, "Virtual Reference in the Music Library," Notes 61, no. 3 (March 2005): 634-58.

5. Beth Christensen, Mary Du Mont, and Alan Green, "Taking Note: Assessing the Performance of Reference Service in Academic Music Libraries: A Progress Report," Notes 58, no. 1 (September 2001): 39-53.

6. Hursh, 63-81.

7. Ibid., 73-74. The sixth factor, philosophy of music library staff members with regard to maintenance of a reference desk, consisted of two variables: librarian-rated importance of regularly scheduled reference service (which was positively correlated), and the perceived effectiveness of the library's current reference situation (which was not statistically significant, but still revealing). 
8. Ibid., 67,69 .

9. Two examples are David Lasocki, "Music Reference as a Calling: An Essay," Notes 56, no. 4 (June 2000): 879-93; and Jane Gottlieb, "Reference Service for Performing Musicians: Understanding and Meeting Their Needs," The Reference Librarian 47 (1994): 47-59.

10. Studies investigating the design of the reference desk include Larry Larason and Judith Schiek Robinson, "The Reference Desk: Service Point or Barrier?" $R Q 23$ (Spring 1984): 332-38, a case study in how reference desk design and positioning affects use; Linda Morgan, "Patron Preference in Reference Service Points," RQ 19 (Summer 1980): 373-75, another case study which observed patrons preferred a counter to a desk for reference service; Robert Pierson, "Appropriate Settings for Reference Service," Reference Services Review 13 (Fall 1985): 13-29, a discussion and presentation of numerous arrangements for a reference area; Lisa R. Bartle, "Designing an Active Academic Reference Service Point," Reference \& User Services Quarterly 38, no. 4 (Summer 1999): 395-401, which proposes a reference service point design based on patron preference in service points, personal space theory, ergonomics, and signage.

11. See, for example, Linnea Hendrickson, "Deskless Reference Services," Catholic Library World 55 (September 1983): 81-82.

12. Published material dealing with the topic includes the following: Hendrickson, 81-84, argues for expanding outreach and refocusing but not eliminating a referencetype service point; Mary Biggs, "Replacing the Fast Fact Drop-In with Gourmet Information Service: A Symposium" (and responses), The Journal of Academic Librarianship 11, no. 2 (May 1985): 68-70, a collection of ideological pieces, none of which actually argue for completely eliminating the reference desk; Wendy L. Helmstetter, et al., "Planning for the Future: Eliminating the Academic Library Reference Desk," Florida Libraries 41, no. 7 (1998): 145-48, details the establishment of a single service point staffed by librarians and extensively trained paraprofessionals, not student assistants, but provides no evaluation (subjective or objective) of the project's success; and Lisa R. Bartle, "Designing an Active Academic Reference Service Point," Reference \& User Services Quarterly 38, no. 4 (Summer 1999): 395401, summarizes the reference desk debates and concludes there is "an overwhelming resolve to maintain the reference service point."

13. Music Library Association Statistics Subcommittee, 2003-2004 Survey of Music Collections in the United States: Academic Libraries (n.p.: Music Library Association, [2004?]), http://www.musiclibraryassoc.org/pdf/statistics/statssurveyresults _0304_academic.pdf. 2003-2004 is the most recent year for which data are available.

14. Ibid., 3.

15. Ibid., 5. Forty-nine percent of music libraries supporting a music program where the master's was the highest degree were open between 75 and 99 hours per week.

16. Ibid., 8. Average staffing for music libraries supporting a music program where the master's was the highest degree consisted of 1.32 MLS-holding staff members and 1.65 support staff members. 
17. Hursh, 70 .

18. Among full-time staff members, the ECU Music Library made no distinction between librarians and paraprofessionals. Paraprofessionals answered any question they felt comfortable with, referring more difficult questions to a librarian. The paraprofessional/librarian referral system worked smoothly.

19. Christensen, Du Mont, and Green, "Taking Note," 52. This study found use of student assistants to answer reference questions had a consistently detrimental effect on reference performance.

20. Since Fall 2003, the ECU Music Library has kept exact reference statistics including the number, type, and time of questions. The library records questions rather than transactions. A single transaction may contain multiple questions.

21. Joan C. Durrance, "Factors That Influence Reference Success: What Makes Questioners Willing to Return?" The Reference Librarian 49/50 (1995): 243-65.

22. The ECU Music Library defines the following four categories of questions: Directional: Where are the bathrooms? Where are the computers? How do you spell "Debussy"?; Technical: Questions about computer hardware, software, printing, and photocopying; Reference: How do I find books about popular music? How do you use the library catalog? How do I find journal articles about James Brown?; Consultation: Library tours and orientations, prearranged research consultations, bibliographic instruction sessions, and any question requiring more than 15 minutes to answer.

23. A level of statistical probability below .05 indicates that the likelihood of the findings occurring by chance is less than five times out of one hundred, or one out of twenty. Statistical significance exists in such cases.

24. Chi Square is a statistical calculation that tests the degree to which the distribution of a set of study data differs from what would be expected to occur by chance.

25. The Table of Significant Differences Between Percentages is based on Chi Square and indicates the minimum percentages necessary to achieve statistical significance. Two factors affect the magnitude needed for a difference to achieve this statistical significance: (1) the total number of responses gathered, and (2) how close the compared percentages are to $50 \%$. Greater differences are required for smaller total numbers of responses and percentages closer to $50 \%$, whereas lesser differences are required for larger total numbers of responses and percentages further from $50 \%$.

26. All totals have been rounded to the nearest whole percentage and therefore may not add to $100 \%$.

27. According to the Table of Significant Differences Between Percentages, when comparing two groups that both have at least 90 respondents, if the percentage nearest $50 \%$ falls between $41 \%$ and $59 \%$, the two groups must have a difference of at least 15 percentage points in order to be significant.

28. Durrance, 257.

29. Larry Larason and Judith Schiek Robinson, "The Reference Desk: Service Point or Barrier?" RQ 23 (Spring 1984): 336.

30. Hursh, 72-73.

31. Ibid., $72-74$. 


\section{WORKS CITED}

Christensen, Beth, Mary Du Mont, and Alan Green. "Taking Note: Assessing the Performance of Reference Service in Academic Music Libraries: A Progress Report." Notes 58, no. 1 (September 2001): 39-54.

Durrance, Joan C. "Factors That Influence Reference Success: What Makes Questioners Willing to Return?" The Reference Librarian 49/50 (1995): 243-65.

Hursh, David. "Calling All Academic Music Library Reference Desks." Music Reference Services Quarterly 8, no. 3 (2004): 63-81.

Larason, Larry, and Judith Schiek Robinson. "The Reference Desk: Service Point or Barrier?" RQ 23 (Spring 1984): 332-38.

Music Library Association Statistics Subcommittee. 2003-2004 Survey of Music Collections in the United States: Academic Libraries. N.p.: Music Library Association, (2004). http://www.musiclibraryassoc.org/pdf/statistics/statssurveyresults _0304_academic.pdf.

Szymanski, Gerald, and Mary Alice Fields. "Virtual Reference in the Music Library." Notes 61, no. 3 (March 2005): 634-58. 


\section{APPENDIX A: SURVEY INSTRUMENT}

\section{ECU Music Library Reference Service Survey}

The Music Library invites you to assist with evaluating our reference service by completing a survey. By participating you agree to the use of your data in a study, but we are collecting no data that could personally identify you. Thanks for your help.

For each question, circle the ONE response that best describes your answer.

1. A reference desk is located in the reference collection, and a librarian is there at selected times to answer questions. Before today, were you aware that the Music Library has a reference desk?

$$
\begin{aligned}
& 1 \text { - Yes (continue with question 2) } \\
& 2 \text { - No (skip to question 7) }
\end{aligned}
$$

2. Have you ever asked a question at the Music Library reference desk?

$$
\begin{aligned}
& 1 \text { - Yes } \\
& 2 \text { - No }
\end{aligned}
$$

For each of the following situations, circle the one number which best represents the likelihood of your taking each course of action, with $1=$ very unlikely and $4=$ very likely

3. If you have a question you can't answer and there is a librarian at the reference desk what is the likelihood that you would:
A. Ask the librarian at the reference desk
B. Seek out a full-time staff member elsewhere in the library
C. Ask a student worker at the circulation desk to help you
2
2
1
1
2
2 etc.)
E. Give up
3
3
4
4
4
4
2
4

Very Somewhat Somewhat Very Unlikely Unlikely Likely Likely 
4. If you have a question you can't answer and there is NO librarian at the reference desk, what is the likelihood that you would:
A. Come back later when a librarian will be at the 1 reference desk
B. Seek out a full-time staff member elsewhere in the library
C. Ask a student worker at the circulation desk to 1 help you
D. Ask someone else (professor, classmate, etc.)
E. Give up

$\begin{array}{lll}2 & 3 & 4 \\ 2 & 3 & 4 \\ 2 & 3 & 4 \\ 2 & 3 & 4 \\ 2 & 3 & 4\end{array}$

5. Did you visit the Music Library before January 2006 ?

$$
\begin{aligned}
& 1 \text { - Yes (continue with question 6) } \\
& 2 \text { - No (skip to question 7) }
\end{aligned}
$$

6. The Music Library reference desk was established in January 2006. Prior to January 2006, if you had a question you couldn't answer, what is the likelihood that you would have:
A. Sought out a full-time staff member
B. Asked a student worker at the circulation

1
1
1
$\begin{array}{lll}2 & 3 & 4 \\ 2 & 3 & 4\end{array}$ desk to help you
C. Asked someone else (professor, classmate, etc.)
D. Given up

1
2
3
4
12
3
4

7. Circle the one category which best describes your current status at ECU.
1 - Freshman
2 - Sophomore
3 - Junior
4 - Senior

5 - Graduate student

$$
\begin{aligned}
& 6 \text { - Faculty } \\
& 7 \text { - Staff } \\
& 8 \text { - Other (please } \\
& \text { describe) }
\end{aligned}
$$

8. On average, how often do you visit the Music Library?

\footnotetext{
1 - Daily, or most days

2 - Weekly

3 - Every other week
}

4 - Monthly

5 - Less than once a month

6 - Today is my first time to visit the Music Library 